\section{Raízes}

Vol. 22, $\mathrm{N}^{\mathrm{o}} 01$, jan.-jun./2003

Trabalho recebido em 12/09/2003

Aprovado para publicação em 09/03/2004
Bernard ROUX

INRA (França), UMR Economie Publique

\title{
AGRICULTORES E IMIGRANTES NA EUROPA DO SUL: ESTRATÉGIAS SEM MARGEM DE MANOBRA
}

\begin{abstract}
RESUMO
Na região andaluza, no sul da Espanha, encontra-se concentrada uma grande produção de frutas e legumes, da qual mais da metade é exportada para toda a União européia. Esta produção se desenvolve nas explorações familiares, com métodos muito intensivos, as vezes em capital e em trabalho, aplicando técnicas avançadas, graças a uma força de trabalho proveniente do estrangeiro (Marrocos, África, América Latina e atualmente da Europa do Leste), assalariada a baixos preços. O artigo estuda as modalidades e os mecanismos do emprego de trabalhadores imigrados que fornecem esta força de trabalho temporária. Para os produtores, a utilização dos imigrantes permite completar a força de trabalho familiar, bastante insuficiente nos períodos de pique. Para os imigrantes a demanda dos produtores oferece a possibilidade de um emprego a trabalhadores sem qualificação, normalmente clandestinos e sem recursos. Nesse mercado de trabalho dominado pelos agricultores, o emprego dos imigrantes constitui um fator decisivo de redução de custos na concorrência em que se confrontam as regiões européias e a bacia mediterrânea para a produção de frutas e legumes.
\end{abstract}

Palavras chaves: Europa, agricultura intensiva, frutas e verduras, agricultura familiar, trabalho temporário, imigrações.

\section{FARMERS AND IMIGRANTS IN SOUTH EUROPE: STRATEGIES WITH NO CHOICES}

\begin{abstract}
SUMARY
The south of Spain (Andalusia) produces large quantities of fruits and vegetables. More than half of the output is exported in the countries of the European Union. Production is on family farms and is both capital and labor intensive, using advanced technology. One of the factors in its development was the employment of low-wage migrant labor (from Marocco, sub-Saharan Africa, Latin America and Eastern Europe).This paper examines patterns and methods of seasonal labor force employment in this sector. From the farmer's point of view, migrant labor supplements the family labor force when it is insufficient at peak production periods. From the migrant's point of view, the demand for seasonal labor provides a job for an unskilled worker who is often undocumented and destitute. On a labor market dominated by farmers, the use of migrant labor is a decisive factor in reducing the cost of fruit and vegetable production in the competition among European and Mediterranean regions.
\end{abstract}

Key words: Europe, intensive agriculture, fruits and vegetables, family farm, seasonal labour, immigration. 


\section{INTRODUÇÃO}

Os agricultores mediterrâneos têm um papel preponderante no abastecimento do mercado europeu de frutas e legumes, em particular no que se refere aos produtos precoces. A concorrência entre zonas de produção se dá em dois níveis: o primeiro é aquele da bacia mediterrânea em relação às regiões situadas ao norte da Europa e no hemisfério sul. Em todos os países da bacia, o peso das frutas e legumes na produção agrícola e nos regimes alimentares é amplamente superior àqueles que se encontram nos países setentrionais europeus. Esta situação torna os países mediterrâneos grandes consumidores e, ao mesmo tempo, importantes exportadores desses produtos. O segundo nível de concorrência é aquele entre regiões mediterrâneas. No conjunto da bacia, a concorrência regional se exprime através de características climáticas e geográficas, dos recursos naturais, do nível de desenvolvimento econômico, da organização econômica e social, da produção e das modalidades de acesso ao mercado da União Européia (UE).

Sob efeito do crescimento das trocas mercantis, ligadas em particular ao mercado comum europeu, certas regiões do Mediterrâneo têm levado vantagem sobre as outras em algumas áreas: precocidade dos produtos, custos de produção, comercialização e transportes. Com esta rude competição apareceram focos regionais de desenvolvimento agrícola cuja emergência não se pensaria há trinta anos atrás. É o caso, por exemplo, da cultura de produtos precoces em Andaluzia: legumes da província de Almeria, morangos da província de Huelva, ou ainda dos tomates do Souss Massa, no Marrocos.

Ora, esses produtos são obtidos com grandes quantidades de capital e de trabalho, o que confere às condições de acesso à mão de obra um papel determinante na eficácia econômica das unidades de produção. Em poucas palavras, a minimização do custo do trabalho é uma das chaves da competitividade. Daí porque a questão do livre mercado euro-mediterrâneo suscita tantas controvérsias. Os países do sul e do leste do Mediterrâneo (PSEM) dispõem de uma vantagem neste domínio sobre aqueles do sul da Europa e reivindicam a possibilidade de se expressar, enquanto que a UE leva à mal a idéia de abandonar seu protecionismo (Regnault \& Roux, 2001). Disso se explica o fato de o tema da imigração, tão conflituosa no seio da EU, interferir na agricultura. É que de fato uma boa parte do sucesso das regiões sul-européias produtoras de frutas e legumes é baseada no emprego da mão de obra imigrada.
Assim, são dois os problemas essenciais postos pela construção da zona de prosperidade euro-mediterrânea, proposta pela Conferência de Barcelona em 1995: a organização dos mercados agrícolas e dos fluxos das pessoas, os quais se cruzam no coração das regiões mais emblemáticas da agricultura mediterrânea. Há três décadas, os agricultores sul-europeus e os imigrantes não pareciam ter nenhuma razão de se encontrarem, mas, atualmente, suas vidas estão ligadas no seio de sistemas agrários totalmente implicados na concorrência internacional. Esses grupos sociais perseguem objetivos e estratégias bem diferentes, mas encontram razões de se unir para satisfazer seus respectivos interesses, às vezes ao preço de conflitos que atingem uma grande violência, como foi o caso, em fevereiro de 2000, na província de Almeiria (Fórum Cívico Europeu, 2000).

Este artigo, portanto, irá tratar sobre a economia dos estabelecimentos de agricultura intensiva e do papel que tem nela a mão de obra imigrante, a partir do estudo da cultura intensiva de legumes em Andaluzia e de uma retomada da temática da imigração na historia agrária da agricultura mediterrânea.

\section{ASPECTOS HISTÓRICOS: A AGRICULTURA MEDITERRÂNEA COMO RECEPTORA E PROVEDORA TRADICIONAL DE MÃO DE OBRA MIGRANTE}

O emprego de trabalhadores sazonais é um elemento chave da economia agrícola em geral e da agricultura mediterrânea em particular: isso se explica pelo ciclo biológico da produção que leva à concentração de certas tarefas no tempo e pela dificuldade, ou mesmo pela impossibilidade, de mecanizar algumas dessas tarefas. Nos momentos em que se desenvolvem estas tarefas, precisa-se empregar quantidades de força de trabalho que ultrapassam, às vezes de longe, como no caso das colheitas, as necessidades correntes das unidades de produção. Trata-se normalmente de uma mão de obra pouco ou não qualificada, recebendo então baixos salários. Essa mão de obra provém de um mercado de trabalho muito extenso e disperso geograficamente e cuja oferta é muito diversificada. A área de procedência sazonal tende a crescer: não é tão difícil de encontrar, por exemplo, búlgaros ou colombianos colhendo morangos no sul da Espanha.

As necessidades de mão de obra e, em particular, da mão de obra temporária, diminuíram consideravelmen-

Raízes, Campina Grande, vol. 22, nº 01, p. 14-23, jan.jjun. 2003 
te devido à mecanização da maior parte dos trabalhos. Em virtude disso, os movimentos sazonais também diminuíram bastante, mas eles mantêm uma importância estratégica no que se refere à produção de frutas e legumes. Certos fluxos importantes, como aquele dos espanhóis e portugueses que vêm para a colheita da uva na França, estão esgotados pela generalização das máquinas, enquanto que as migrações temporárias tinham características de dupla função na agricultura mediterrânea: a emissão e a recepção de mão de obra sazonal.

$\mathrm{Na}$ Europa do sul, de fato, em certas regiões de forte concentração de terras, como Andaluzia, Alentejo ou a Cicília, ha muito tempo a agricultura elegeu o trabalhador temporário como uma figura imprescindível aos seus sistemas de produção. A estrutura agrária, constituída, de um lado, de pequenas e muito pequenas áreas de explorações (minifúndio) e, de outro, de grandes áreas de explorações (latifúndio), repousa sobre o trabalho assalariado, criando, ao mesmo tempo, uma demanda e uma oferta específicas de força de trabalho. As famílias de minifundistas, juntamente com as dos camponeses sem terra, constituíam o reservatório de trabalhadores ao qual recorrem os latifúndios em função de suas necessidades a cada período do ano. O trabalhador contratado por semana, permitiria a melhor aplicação da estratégia dos grandes agricultores: ajustar a força de trabalho realmente utilizada às necessidades dos ciclos de produção.

O subdesenvolvimento e a estrutura agrária contribuem para que partam os contingentes de migrantes espanhóis, portugueses e italianos nos anos sessenta e setenta, vindo trabalhar nas usinas das regiões em forte crescimento de seus próprios países e da Europa do norte, mas também nos estabelecimentos agrícolas. Aqueles migrantes vinham para a agricultura geralmente a título temporário, no âmbito contratual mais ou menos respeitado nos países de proveniência bem como nos de chegada. Ao mesmo tempo que se produziam esses movimentos internacionais de força de trabalho, suprindo, para muitos, as necessidades das cadeias de frutas e legumes, no interior dos países da Europa do sul continuava a se exprimir uma demanda tradicional de sazonais em direção aos pontos de trabalho dos sistemas mediterrâneos, como a colheita de olivas.

E neste contexto tradicional de emissão-recepção de força de trabalho no seio da agricultura mediterrânea que iria se produzir, em certas regiões da Europa do sul, uma reestruturação e um aumento da demanda de trabalhadores agrícolas sazonais.

Raízes, Campina Grande, vol. 22, nº 01, p. 14-23, jan./jun. 2003

\section{A EXPANSÃO DA DEMANDA DE FORÇA DE TRABALHO TEMPORÁRIO NAS REGIÕES ESPECIALIZADAS EM FRUTAS E LEGUMES}

Com a diversificação e o crescimento da demanda alimentar observada na Europa e o estabelecimento de um mercado progressivamente unificado no seio da UE, as regiões mediterrâneas, notadamente a Espanha, capazes de mobilizar vantagens comparativas, especializaram-se na cultura de frutas e legumes. Foi o caso de certas zonas litorâneas andaluzas de onde começaram a ser exportadas quantidades notáveis de frutas e legumes desde 1970, fato que prolongava uma velha tradição exportadora espanhola, notadamente de cítricos valencianos. O desenvolvimento agrícola como resultado suscitou numerosos estudos mostrando sua originalidade (Molina e Provansal, 1989; Olea Porcel,1986; Roux, 1995).

Os sistemas de produção que se desenvolveram se baseiam na inovação tecnológica; no emprego de quantidades elevadas de capital e de produtos da indústria química; na utilização de água e em grande recurso de mão de obra. Trata-se então, de uma agricultura muito intensiva em capital e em trabalho, predominantemente realizada em estufas. A densidade elevada de força de trabalho devese ao fato de que a maior parte das tarefas não são mecanizadas (e não mecanizáveis no estado atual das técnicas), como é o caso da plantação, dos tratamentos em curso de vegetação ou de colheitas.

No litoral de Andaluzia, vários centros de desenvolvimento foram aparecendo sob o efeito combinado de iniciativas locais e externas. Os esforços das instituições bancárias regionais, como aqueles dos organismos profissionais promotores de técnicas culturais adaptadas às condições naturais, conjugaram-se aos impulsos externos à região e à agricultura, vindo do transporte rodoviário e da grande distribuição. Os mercados mais longínquos da UE são agora abastecidos pelas zonas, como o litoral da província de Almeria (legumes) e o litoral da província de Huelva (morangos), enquanto que o litoral da província de Cadix começa sua especialização nas culturas florais.

Esta agricultura moderna, altamente produtiva, de um nível tecnológico considerável, compõe-se em sua grande maioria de unidades de produção familiar. As raras tentativas de constituição de empresas baseadas exclusivamente sobre o assalariamento não tiveram bons resultados. A rentabilidade dos investimentos necessários à aquisição da terra e dos equipamentos era muito alta e o capital circu- 
lante muito fraco em relação a taxa de lucro médio. Assim, impõe-se a pequena organização familiar graças, principalmente, a pequena taxa real de remuneração da força de trabalho aceita pelos membros da família.

Mas, considerando a natureza intensiva dos sistemas de produção e de evolução social dessas famílias de agricultores, a força de trabalho gerada no seio do grupo familiar não é suficiente para satisfazer as necessidades. Durante vários períodos do ciclo de produção, a colheita, principalmente, a demanda de trabalho excede em muito as possibilidades oferecidas para a única unidade de produção: empregar mão de obra temporária é uma questão de sobrevivência econômica. Durante algum tempo, pode-se apelar para o grupo familiar maior, e para contratados, mas esta eventualidade é cada vez mais aleatória para não dizer impossível. É preciso, então, concentrar-se no mercado de trabalho. Ademais, o aumento do nível de vida das famílias de agricultores e a modificação geral do esforço manual reduzem o volume da força de trabalho mobilizável no seio da família: cada vez mais, o chefe do estabelecimento constitui o único trabalhador da unidade de produção, o que se constitui numa causa a mais para o recurso ao trabalho assalariado.

Assim, a extensão da produção intensiva de frutas e legumes no sul da Espanha, concentrada nas zonas de superfície restrita, constitui uma espécie de réstia sobre o litoral mediterrâneo, sendo acompanhada de um aumento constante da demanda de mão de obra temporária assalariada.

\section{IMIGRAÇÃO, RESERVATÓRIO INESGOTÁVEL DE FORÇA DE TRABALHO PARA A AGRICULTURA INTENSIVA EUROPÉIA}

Atualmente, a demanda de mão de obra temporária assalariada é, praticamente, constituída pelos trabalhadores imigrados. Esta situação pode parecer paradoxal quando se sabe que a Andaluzia é uma das regiões onde se constata as mais altas taxas de desemprego agrícola da UE. Para explicar isto é necessário compreender o modo de funcionamento dos estabelecimentos familiares. Em princípio, essas unidades da agricultura intensiva procuram, em primeiro lugar e por definição, a força de trabalho da qual elas têm necessidade no grupo familiar restrito ou amplo (cônjuge, filhos, pais), a fim de minimizar o custo. Porém, dois fatores principais levaram os agricultores a se dedicarem sistematicamente ao trabalho assalariado: de uma parte, a menor disponibilidade da família; de outra parte, o crescimento interno dos estabelecimentos. Este último fator foi possibilitado pelo aumento da renda através do crescimento do volume de produção: cada agricultor se esforça para intensificar e/ou aumentar seu estabelecimento, o que leva a uma maior necessidade de mão de obra. O mercado de trabalho é então o único meio de satisfazê-lo.

Devido a esta demanda, os trabalhadores andaluzos oferecem cada vez menos sua força de trabalho e são, inclusive, pouco procurados. No local, as atividades alternativas não faltam, porque as zonas de produção agrícola intensiva são litorâneas: a construção e o turismo oferecem melhores possibilidades que a agricultura, já que se trata de um trabalho penoso e remunerado ao nível mais baixo da escala dos salários. As bolsas de desemprego em Andaluzia se situam, principalmente nas regiões menos desenvolvidas, distantes ou mesmo encravadas, onde as ajudas aos trabalhadores agrícolas desempregados — instituídas depois de muito tempo - , dissuadem amplamente a procura do trabalho distante. Existem, ainda, deslocamentos de mão de obra correspondente a atividades bem específicas, mas eles se rarefazem. É o caso, por exemplo, da colheita de morangos da província de Huelva, da qual participam famílias vindas da Sierra Morena, residindo há uma centena de quilômetros de lá. São então numerosos os fatores explicativos da fraca participação da mão de obra andaluza no trabalho sazonal nos estabelecimentos da agricultura intensiva: os baixos salários, a penúria das tarefas, a concorrência dos outros setores, as ajudas sociais constituem também outros entraves. Mas um fator importa sobre todos os outros: a existência de um fluxo permanente de imigrantes prontos a aceitar as piores condições de trabalho.

A proximidade do Marrocos não é evidentemente estranha a isso. Desde os anos 1970, o desenvolvimento da agricultura intensiva atraiu candidatos magrebinos e africanos para os quais o estreito de Gibraltar constituía uma porta de entrada natural à emigração. A perspectiva de um emprego na agricultura era precária, mal paga e penosa, levando à esperança por dias melhores na direção da Espanha ou mais ao norte da UE. Assim vieram dezenas de milhares de imigrantes, dos quais uma parte se encontra como diaristas agrícolas em estabelecimentos intensivos. Discreta no inicio, porque a maioria dos imigrados se encontrava em situação irregular, sua presença começou nos anos 1980, primeiro pela aplicação da lei sobre os estrangeiros adotada pela Espanha em 1985, para preparar sua entrada na UE, depois pela aplicação

Raízes, Campina Grande, vol. 22, nº 01, p. 14-23, jan./jun. 2003 
das medidas "Schengen".

Em meados dos anos 1990, as associações caritativas estimavam em 5000 (apenas na região de Almeria) o numero dos imigrados trabalhando na agricultura, principalmente de marroquinos. Os números atuais mostram que o fluxo desta imigração foi consideravelmente reforçado, pois se contava em torno de 35000 estrangeiros na mesma região, no início dos anos 2000, dos quais somente 9200 seriam oficialmente registrados, o que confirma o papel considerável do trabalho não declarado nesta economia (Fórum Cívico Europeu, 2002).

Depois que a UE endureceu sua política contra a imigração, a grande maioria das entradas pelo estreito de Gibraltar se faz graças a meios ilegais, notadamente pelas famosas "pateras", embarcações pertencentes a pessoas mais ou menos mafiosas, que transportam clandestinos a preço de ouro, correndo muitos riscos. Sabe-se que a má sorte espera uma parte dentre eles, que perecem no mar quando dos naufrágios dessas precárias embarcações (um milhão, segundo certas estimativas dos últimos anos). Entre aqueles que não são interceptados pela polícia (cerca de 17000 prisões, em 2000), um bom número faz uma parada nos estabelecimentos do litoral, trabalhando para os agricultores da área, os quais ficam felizes por ter à sua disposição essa mão de obra que não faz muitas exigências em termos de salários.

A África não é a única fonte de imigração útil aos horticultores do sul da Espanha. Depois dos magrebinos e dos africanos, no final dos anos 1990, ocorreu a chegada dos "latinos". A Espanha, de fato, por razões históricas e culturais, recebe um fluxo contínuo de imigrantes da América latina, principalmente dos países andinos e poucos também vindos da Argentina. Tendo conhecimento da oferta de trabalho da agricultura intensiva, numerosos desses novos imigrantes se apresentam aos fazendeiros na busca de seu primeiro emprego.

Enfim, uma nova onda de imigrantes vindos de países da Europa central e oriental toma vulto depois de pouco tempo. Os violentos acontecimentos racistas ocorridos no município de El Ejido, em fevereiro de 2000, dos quais foram vÍtimas os trabalhadores marroquinos, não são estranhos a esses novos fluxos migratórios: na busca de meios de sobreviver, novas comunidades estão sempre prontas a oferecer seus serviços em detrimento da comunidade estigmatizada.

Assim, os agricultores não têm outra escolha: imigrantes cada vez mais numerosos e de origens as mais diversas batem continuamente nas suas portas. Pode-se afirmar que a imigração constituirá, ainda muito tempo, uma fonte inesgotável de força de trabalho barata para a agricultura intensiva mediterrânea européia.

\section{MECANISMOS ECONÔMICOS DE EMPREGO DOS IMIGRANTES: AS ESTRATÉGIAS DOS AGRICULTORES}

Lembramos acima as razões ligadas às características dos sistemas de produção, para as quais os estabelecimentos familiares que produzem frutas e legumes são obrigados a completar sua própria força de trabalho utilizando uma mão de obra assalariada. Atualmente, é preciso juntar este aspecto da agricultura intensiva mediterrânea ao fato de que esses assalariados são, na maioria, imigrantes ou pessoas com status social próximo àquele dos imigrantes, como é o caso dos gitanos. Caberia perguntar porque, nas condições econômicas atuais, não poderia ser diferente.

Esses produtores são submetidos às pressões de um mercado extremamente competitivo no seio da UE. Todas as regiões mediterrâneas européias, do sul de Portugal à Grécia, à condição de dispor de água para irrigar, são suscetíveis de produzir produtos precoces, num período em que o mercado europeu já está saturado. A grande distribuição, que comercializa $60 \%$ das frutas e legumes, repassa esta situação ao mercado, impondo preços sempre baixos. Ora, os horticultores europeus não se beneficiam de um apoio significativo da Política Agrícola Comum (PAC), mesmo tendo dispositivos que lhes protegem parcialmente de outros países, inclusive os PSEM (Países do Sul e do Leste do Mediterrâneo) e algumas medidas de retração em caso de uma super produção. Logo, esses horticultores concentram suas preocupações no plano dos calendários de produção e de custos. Os meios que eles utilizam são os mesmos em todos os lugares: proveito de vantagens comparativas climáticas, ganhos de produtividade tecnológica, economias de escala e redução de encargos.

Nessa competição, os produtores de frutas e legumes precoces andaluzes puderam e souberam tomar decisões favoráveis em muitas dessas áreas. As vantagens de um clima particularmente favorável no inverno foram valorizadas pelos equipamentos e técnicas de produção sob abrigo instalado localmente (as estufas frias com cobertura de plástico de Almeiria). Tecnologias avançadas, em termos de sementes, de fertilização e de irrigação são generalizadas e a comercialização se faz através de méto- 
dos impostos pelo mercado e por empresas de armazenamento e de transporte eficazes. Entretanto, a margem de benefício que resta nas mãos do agricultor está em constante baixa. Os agricultores tentam reduzir os custos da mão de obra sempre que possível, porque elas representam uma parte elevada dos custos variáveis, às vezes até $50 \%$. É nesse contexto que intervem a presença dos imigrantes.

Para atingir da melhor maneira possível, tanto em quantidade quanto em qualidade, as condições impostas pelo mercado, em matéria de regularidade das entregas, os agricultores necessitam ajustar o tamanho da força de trabalho nos seus estabelecimentos, sem aumentar demasiadamente os custos e sem correr o risco de maquiar qualquer operação, principalmente a colheita. $\mathrm{O}$ mercado de trabalho local satisfaz esta necessidade: a oferta de mão de obra aí é superabundante e totalmente flexível. Ela é composta desses imigrantes de todas as nacionalidades, dos quais uma parte é legalizada e outra clandestina, estando estes prontos a aceitar duras condições de trabalho desde que se garanta o salário estabelecido pelo mercado. Existe uma remuneração diária aceita pelas organizações locais relativas ao emprego agrícola: os sindicatos de produtores, os sindicatos de trabalhadores (pouco poderosos) e a administração. Vale salientar que, em 2001, a diária de trabalho era paga a 5000 pesetas (o equivalente a $30 \mathrm{eu}-$ ros, o que significa cerca de $40 \%$ do custo do trabalho de uma faxineira em Paris), mais os encargos sociais de 900 pesetas (5,4 euros).

Os produtores têm, então, uma estratégia simples de empreendedores, através da qual eles procuram o menor custo do trabalho e o máximo de flexibilidade de emprego, esforçando-se para obter a garantia do trabalho bem feito. É por isso que eles tentam criar laços de confiança com os imigrantes, renovando os contratos sempre com os mesmos operários de um período a outro, favorecendo redes informais entre imigrantes, parentes ou amigos, para enfrentar as variações de necessidade de força de trabalho. Em tal sistema de trabalho, são poucos os operários permanentes. Isso se deve, por um lado, às particularidades dos ciclos de produção, os quais terminam quase todos durante o verão: uma mão de obra contratada sem descontinuidade seria então ociosa; por outro lado, os agricultores querem se livrar dos compromissos com os trabalhadores. Apenas os maiores estabelecimentos, em número bastante reduzido, empregam trabalhadores permanentes, geralmente espanhóis.
Além disso, pelas suas práticas, os agricultores criaram duas categorias de operários temporários. Uma correspondente a um emprego para o período do calendário agrícola, cujos termos são decididos pelo empregador logo que ele estima não mais precisar do seu empregado. Nesse sistema, os trabalhadores garantem de oito a dez meses de trabalho por ano, freqüentemente no mesmo estabelecimento. Esses trabalhadores são geralmente legalizados. Outra categoria é aquela do operário contratado por períodos muito curtos: um dia, alguns dias, uma semana. Entende-se que os clandestinos constituem uma reserva ideal da qual os agricultores podem se servir sem constrangimentos. Em alguns casos são observadas diferenças de remuneração, sendo os clandestinos submetidos a aceitar uma diminuição que pode atingir até $20 \%$ do salário corrente e, às vezes, a não terem consideradas suas horas extras.

Essas estratégias de emprego pelas quais o diarista é considerado uma simples variável de ajustamento do sistema de produção, prolongam as práticas ancestrais dos latifúndios e mesmo aquelas dos estabelecimentos familiares intensivos das "huertas", nos quais os diaristas sempre foram contratados dia a dia. Os salários da agricultura andaluza sempre foram os mais baixos de todos os setores. Essa tradição se perpetua nos sistemas modernos, entretanto com importantes novidades: os agricultores são familiares e não mais apenas capitalistas e os diaristas não são mais andaluzese sim imigrantes.

\section{AS ESTRATÉGIAS DOS IMIGRANTES: O EMPREGO AGRÍCOLA COMO SOLUÇÃO TEMPORÁRIA}

Nas condições de funcionamento desse mercado de trabalho, pode-se falar em estratégias para esses imigrantes? Teriam eles uma margem mínima de manobra? No que diz respeito ao emprego, sabe-se que eles são inteiramente submetidos às decisões dos agricultores, particularmente no que se refere à natureza e à intensidade das tarefas, à forma e duração do contrato. O fato dos imigrantes se encontrarem nessas zonas de agricultura intensiva decorre sempre do projeto desses imigrantes: se a partida para o estrangeiro é vista como única saída para melhorar sua situação e a de seus dependentes, a aceitação do trabalho agrícola, notadamente nas regiões serranas, resta como única alternativa paliativa.

Os imigrantes que vieram nos anos 80 eram, mais freqüentemente, marroquinos e de regiões rurais, tendo

Raízes, Campina Grande, vol. 22, nº 01, p. 14-23, jan./jun. 2003 
uma perspectiva de retorno, indo e vindo em função dos calendários agrícolas. Alguns se acomodaram ao seu status e criaram vínculos duradouros com seus empregadores, continuando seus movimentos pendulares. Nos anos 1990, quando a Europa fechou suas fronteiras, o desejo que os marroquinos tinham de deixar seu país não diminuiu. Na medida em que as perspectivas de emprego se degradaram, a vontade de partir se estendeu até mesmo às camadas sociais mais privilegiadas, inclusive entre os portadores de diploma universitários ${ }^{1}$. Um fluxo contínuo de clandestinos, originários do Marrocos e de vários outros países africanos, utilizando uma rede de transportes cada vez mais bem organizada, chega continuamente pelo estreito de Gibraltar ou via Canárias. Sua estratégia não é evidentemente a de se isolar nas estufas de Almeria. Para alguns dentre eles, o início da aventura européia passará, necessariamente, pelo ingrato trabalho de diarista agrícola.

Os imigrantes da América Latina, vindos apenas há poucos anos, se inscrevem mais freqüentemente num percurso andaluz transitório. Tendo deixado seus países por necessidade econômica, tanto quanto os magrebinos e africanos, eles sempre chegam na esperança que os agricultores não queiram mais os "mouros", sobretudo depois dos conflitos raciais de fevereiro de 2000 e afirmam a vontade de "fazer um pé de meia" para se reinstalar no seu país de origem. Esse é o esquema clássico da "imigração econômica", que raramente chega a se realizar.

Quanto à estratégia dos originários dos países da Europa central e oriental, dos quais muitos são clandestinos, ela também é temporária. A agricultura de Almeria, da qual se ouve falar vagamente, só é procurada como um ganha pão momentâneo, antes de se tentar a sorte em outras profissões mais ligadas ao nível de formação desses imigrantes recentes e em outros países.

Mesmo se seu projeto pode parecer ilusório, os operários estrangeiros das estufas e dos postos de armazenamento (nesses últimos se encontram praticamente apenas mulheres), qualquer que seja sua origem geográfica, vêem, sobretudo, em Andaluzia uma etapa que lhes permitirá regularizar sua situação e continuar "a aventura européia" ou somente espanhola. São poucos os que têm uma estratégia de perenização da sua instalação como operário agrícola (cf. Ladislas, 2001).

As condições de vida desses operários estrangeiros são um reflexo de seu status: "invisibilidade social" e miséria material. Habitando, na maioria dos casos, casebres insalubres (os "cortiços", nas zonas de Almeria) entre as estufas, ou se amontoando em apartamentos dos bairros pobres, se esforçam para passar despercebidos, economizando tanto quanto possível para enviar periodicamente a quantia esperada pela família, como o fazem todos os imigrantes do mundo. Os que vivem com mulher e filhos são raros.

A estratégia cotidiana é mais ou menos a mesma para todos: encontrar trabalho, custe o que custar, utilizando todos os canais informais possíveis. Essa busca de trabalho implica em se apresentar aos agricultores nas proximidades das estufas ou de suas parcelas, em responder a uma intermediação de um amigo ou de um parente, ou, ao amanhecer, comparecer aos pontos de encontro com os empregadores, verdadeiros mercados de diaristas, bem dentro da tradição andaluza. Apesar de tudo, os dias de desemprego são numerosos, já que os agricultores locais são procurados por bem mais trabalhadores do que eles precisam $^{2}$.

O clima de concorrência pelo emprego entre os operários tem crescido gradualmente. Este ano (2002), por exemplo, na região de Huelva, o comportamento dos empregadores produtores de morangos provocou uma tensão mais forte que a de costume: os marroquinos habituados até aqui com a colheita, depararam-se com contingentes de operários temporários vindos da Europa central, chamados num contexto de acordos firmados pela UE. Nessas condições, não é de se admirar que $70 \%$ dos imigrantes entrevistados tenham respondido que, já há alguns anos, "as coisas não iam bem para eles desde sua chegada à Espanha”.

\footnotetext{
${ }^{1}$ Os universitários encontrados entre esses imigrantes acima mencionados têm o projeto de obter sua regularização e abandonar, o mais rápido possível, esse tipo de trabalho (o de trabalhador agrícola temporário), considerado sem perspectivas.

${ }^{2}$ Uma pesquisa realizada junto a duzentos marroquinos e africanos na região de Almeria mostrou que $30 \%$ trabalhavam menos de quatro meses, $20 \%$ entre quatro e seis meses, $37 \%$ entre sete e nove meses e apenas $7 \%$ entre dez e doze meses (5\% não responderam ou não sabiam) (Checa, 1995).

${ }^{3}$ Mesmo assim, $90 \%$ dessa mesma amostra garantiram que "deixar seu país havia sido a melhor decisão" (Checa, 1995).
} 


\section{UM DESENVOLVIMENTO AGRíCOLA ESPETACULAR}

O desenvolvimento dessa agricultura intensiva andaluza, graças à articulação da exploração familiar e da mão de obra imigrada, depois dos anos 1970, impressionou de tal maneira os observadores que se pode utilizar sobre ela o termo "milagre econômico". Há uma semelhança entre entre essa região e a paisagem artificializada, "o mar de plástico” do Campo de Dalias, na planície litorânea próxima de Almeria, na qual foi implantada uma série de estufas, num lugar em que, trinta anos antes, não se viam senão que parcelas pedregosas, o que dá uma sensação de dinamismo que alguns comparam ao que foi vivido outrora no Far West.

De fato, graças a essa produção em estufa, a província de Almeria tem um peso considerável na agricultura de Espanha. As primeiras estufas foram construídas em 1970, segundo as técnicas e materiais locais. Conta-se atualmente com 40.000ha (38966 ha, em 1998), ou seja, $53 \%$ da superfície que ocupa esse tipo de agricultura irrigada nas 50 províncias do país. Com quatro mil e novecentos $h a$, ou seja, em torno de 10 vezes menos do que há um quarto de século (1074), quando a produção não era mais que $42 \%$. Tal evolução, tanto em valor absoluto, quanto relativo, mostra o vigor da especialização regional. As culturas praticadas constituem um pequeno grupo de legumes e frutas (na ordem de superfícies ocupadas: pimentão, tomate, melão, melancia, vagem, pepino, abobrinha e berinjela), representando $60 \%$ das superfícies consagradas a estas culturas, sob abrigo, na Espanha. A província de Huelva fornece $92 \%$ dos morangos precoces espanhóis. Uma proporção significativa dessas produções é exportada: na ordem de $50 \%$ para os produtos de horticultura de Almeria, e de $65 \%$ para os morangos de Huelva. A UE se constitui na destinação quase exclusiva.

Quantas propriedades e quantos imigrantes estão envolvidos nessa agricultura? As estatísticas fornecidas em 1997 pela junta de Andaluzia (apenas pelo campo de Delias), zona da província de Almeria, onde se encontra "el Ejido", palco de conflitos racistas, indicam a mais forte concentração de estufas e um número de 24374 propriedades, para 26109 ha de terras agrícolas, ou seja, uma superfície média por estabelecimento de 1 ha aproximadamente, da qual a metade mais ou menos é cultivada sob abrigo. Para a província, pode-se estimar a 40 mil o número de estabelecimentos dispondo de estufas. Três categorias de agricultores podem ser distinguidas ( $c f$. Betegon,
2001):

- Primeiramente, os menores - mais freqüentes, cuja exploração é inferior a 1 ha, cuja mão de obra é principalmente familiar e o recurso aos diaristas concentra-se no período de colheita. Esses sazonais representam aproximadamente $1 / 3$ da força de trabalho.

- A segunda categoria, formada por aqueles cuja exploração é feita numa área de entre 1 e 4 ha, que empregam 1 operário permanente durante todo o ciclo e um número determinado de diaristas: nesse grupo, a força de trabalho familiar cai até $25 \%$ do total.

- Na terceira categoria, na qual pouco se incluem, a quase totalidade do trabalho é garantida por assalariados, o chefe da atividade não fazendo mais do que trabalho de gestão. Uma estimativa efetuada a partir de entrevistas, permite considerar que entre 40 e $50 \%$ do trabalho total (o equivalente a dois homens empregados por todo o ano por hectare) é fornecido por assalariados. O número de 35000 imigrantes trabalhando nas estufas de Almeria, acima citado, seria coerente com essa estimativa.

Na competição para aprovisionar os mercados da UE, observada nas regiões mediterrâneas, essa combinação entre a necessidade de mão de obra dos agricultores andaluzos e a força de trabalho dos imigrados dá seus frutos. Os lucros dos estabelecimentos diminuíram muito, mas os produtos precoces de Almeria e de Huelva conservam seus lugares no mercado. Uma comparação dos custos de produção de tomates obtidos em Almeria e no Sous Massa, no Marrocos, mostrou, entretanto, que as ameaças provenientes do Sul são bem reais: o custo de produção é bem mais baixo na região marroquina, devido ao preço da mão de obra. Por enquanto, é o custo do transporte que coloca a Almeria na corrida (cf. Calatrava \& Mahfoud, 2002). O paradoxo da situação constitui-se no fato de que não são os baixíssimos salários agrícolas marroquinos que fazem a diferença, mas as baixas remunerações dos imigrantes marroquinos que colocam a Andaluzia na liderança agrícola das regiões da Europa.

Emblema do desenvolvimento desse sistema agrário, el Ejido, antigo vilarejo de "colonização", criado pelo estado franquista em favor dos camponeses pobres da província, tornou-se uma cidade agrícola de 40.000 habitantes, com agências bancárias, escritórios empresariais de transporte, estabelecimentos de armazenamento de frutas e legumes, numerosas estufas, separadas por um anel viário rural e alguns bairros de habitação de agricultores: um conjunto efervescente e composto, imbricando o urbano

Raízes, Campina Grande, vol. 22, nº 01, p. 14-23, jan./jun. 2003 
e o rural, foi constituído no decorrer dos anos. No seu seio e sobre suas margens, os imigrantes vivem em condições materiais difíceis, muitas vezes mesmo deploráveis quando eles moram nas dependências das propriedades agrícolas. A convivência desses numerosos estrangeiros e a população espanhola é tensa, a ponto de ter provocado manifestações racistas violentas, como as de fevereiro de 2000, as quais se tornaram crônicas nessa região.

\section{CONCLUSÃO: NA DIREÇÃO DO MODELO ANDALUZO?}

A situação dessa agricultura andaluza é tanto um sinal de continuidade quanto de ruptura na economia da agricultura mediterrânea. Continuidade, na sua função de provedora dos mercados europeus de frutas e legumes, mas ruptura nas características do mercado de trabalho, este segundo elemento garantindo, em parte, o primeiro. No decorrer dos anos, a chegada sempre diversificada de trabalhadores imigrados criou um volume de força de trabalho largamente suficiente para as necessidades dos produtores, ocupando o lugar dos operários agrícolas locais, tornados raros e reticentes diante das condições dos contratos e do trabalho em si mesmo. Esses fatores são favoráveis à conservação da competitividade dos agricultores: a flexibilidade máxima do emprego e os baixos salários são fatores importantes para reduzir os custos de produção.

Ora, se na agricultura intensiva andaluza o emprego dos imigrantes foi instaurado como elemento estrutural, constata-se também que ele foi difundido em outras áreas da Europa. Lembrou-se aqui o papel dos imigrantes sazonais, há alguns anos, no sul da Europa, atualmente quase extinto. A novidade então não é o recurso a uma mão de obra móvel e flexível, mas, como já descrito no caso de Almeiria, o fato de que a origem dessa força de trabalho se mundialize, escapando largamente às leis da imigração e à legalização do trabalho e que ela se encontre em regiões e sistemas agrários variados.

Exemplos dessa característica atual do mercado de trabalho agrícola europeu e mundial não faltam: na Espanha, encontram-se numerosos marroquinos que trabalham em outras regiões além da citada acima: em Estremadura, na colheita do fumo em propriedades familiares, lá onde sempre os sazonais eram os espanhóis; na pecuária de carneiros, na Mancha, os imigrantes ucranianos ou búlgaros tomam o lugar dos pastores locais. No sul da França, há muito tempo que os operários magrebinos constituem a mão de obra para horticultores e arboricul- tores, mas se encontram também os poloneses. Na Itália do norte, os africanos estão presentes na pecuária. Em Israel, $64 \%$ dos operários agrícolas, que representam um total de $45 \%$ da força de trabalho do setor, são estrangeiros (cf. Shesckin e Regev, 2001), dos quais a quase totalidade é proveniente da Tailândia. Na Inglaterra, o sistema dos "gangmasters" que pode se traduzir como "chefes de equipes” que existe desde muito tempo e cuja função é de fazer a intermediação, respondendo à demanda de diaristas para os produtores, recruta atualmente cada vez mais entre os clandestinos de Europa Central e oriental. Na Holanda o trabalho na estufa é largamente garantido pelos imigrantes de todas as regiões, mais ou menos como em Andaluzia. Na Áustria e na Alemanha, a mão de obra polonesa, tcheca e húngara está presente nas propriedades que precisam de braços no período da colheita.

O "modelo andaluz" é, então, um exemplo da imbricação da economia agrícola com a imigração. Sua razão de ser, a corrida pela competitividade, não é questionada. Ao contrário, graças ao fluxo de imigrantes do Magrebe e da África, como também da Europa central e oriental, da América Latina e da Ásia, os agricultores da UE podem se aproveitar de uma mão de obra barata e servil. Isto é um elemento importante que deve ser levado em conta para se analisar as relações das agriculturas da UE com as de outras regiões ainda não incluídas. Não é um efeito paradoxal que os agricultores da UE tirem uma parte de sua competitividade dos agricultores dos países acima citados como originários do fluxo de imigrantes, do emprego de trabalhadores que foram obrigados a abandoná-los na esperanças de melhorar suas condições de vida?

\section{REFERÊNCIAS BIBLIOGRÁFICAS}

BARBOLLA CAMARERO D., 2001, "Immigracion marroqui en la zona de Talayuela” (Caceres), Editora regional de Extremadura, Merida

BETEGON B., 2001, "Etude du système agraire de El Ejido: un exemple d'agriculture intensive sous abri plastique", Mémoire de DESS, Développement agricole, IEDES, Université Paris I, 70 p.

CALATRAVA J. et MAHFOUD Y., 2001, "La concurrence entre le Maroc et l'Espagne sur le marché européen de la tomate", In REGNAULT H. et ROUX B. (Dir), Relations euro-méditerranéennes et libéralisation 
agricole, L'Harmattan, Paris, pp147-171.

CHECA F., 1995, "Migracion, riesgo y beneficio. Los immigrantes africanos en la provincia de Almeria.”, Demofilo $n^{\circ} 15$, Fundacion Machado, Seville, pp 103-134.

FORUM CIVIQUE EUROPEEN, 2001, "El Ejido, terre de non droit. Rapport d'une commission internationale sur les émeutes racistes de février 2000 en Andalousie", Co-édition Forum civique européen, Comité européen de défense des réfugiés et immigrés, Bâle/Limans, 119 p.

FORUM CIVIQUE EUROPEEN, 2002, "Le goût amer de nos fruits et légumes. L'exploitation des migrants dans l'agriculture intensive en Eiurope", Informations et commentaires, $\mathrm{n}^{\mathrm{o}}$ hors série, mars, Co-édition Forum civique européen, Association pour un nouveau développement, Limans/Corenc, 131 p.

LADISLAS M., 2001, "Marché du travail et relations sociales dans les serres d'El Ejido “, Mémoire de fin d'étude, INA PG, Paris, 92 p.

MOLINA P. et PROVANSAL D., 1989, "Campo de Nijar: cortijeros y areneros", Instituto de estudios almerienses. Diputacion de Almeria, $451 \mathrm{p}$

OLEA PORCEL B., 1985," Empresas agrarias de cultivos intensivos en la Costa del sol. ", Universidad de Malaga, $333 \mathrm{p}$.

REGNAULT H. et ROUX B., 2001, "Relations euro- méditerranéennes et libéralisation agricole”, LHarmattan, Paris, 299 p.

ROUX B., 1995, "Estado, agricultura familiar y modernidad: el desarrollo de la horticultura intensiva en las regiones litorales del sur de Espana”, Demofilo $n^{\circ} 15$, Fundacion Machado, Seville, pp 87-102

SHESKIN A. et REGEV A., 2001, "Israël agriculture. Facts and figures", Ministery of agriculture and rural development, Beit Dagan, 33p. 